\title{
Local Roots, Global aspirations: Impact of culture on work environment and organizational culture in Malaysian Small and Medium Enterprises in the Information Technology Sector
}

\author{
Vandana Saxena ${ }^{1, *}$, and Anindita Dasgupta ${ }^{1}$ \\ ${ }^{1}$ Taylor's University, Malaysia
}

\begin{abstract}
This paper investigates the role of culture in hiring, team formations and workplace interactions in Malaysian small and medium enterprises (SME) in the Information and Communication Technology (ICT) sector. This research used the case study approach, with multimethod data collecting instruments like observation, interviews, and analysis of the data available on the websites of the two ICT SMEs under study. The participants selected for the study were the owners, managers and senior employees of both firms. While both firms operated in similar fields, the workforce of one consisted largely of Malaysian employees, while that of second company consisted largely of foreigners. The findings revealed a considerable bias and preference towards cultural homogeneity.
\end{abstract}

\section{Introduction}

Does culture play a role in the hiring, team formations and workplace interactions of professionals in Malaysian ICT SMEs? If yes, then is it a peripheral factor, or does it exert a significant influence on these organization practices and thus shape the nationality and social demographics of the ICT sector in Malaysia? Existing studies are divided over the role culture plays in labour market stratification. [2,3] have argued that culture is peripheral to occupational sorting, while [10] contend that culture is an important basis on which symbolic rewards like access to desirable jobs, recognition and status — are distributed. Lauren Rivera, a prominent researcher in the field of cultural sociology and social stratification, argues that the decision to hire an employee, a crucial moment in labour market stratification, is actually a process of "cultural matching" between candidates, evaluators and firms. Shared culture often outweighs the concerns about absolute productivity of an employee [13].

This study is an attempt to unpack cultural dynamics that come into play during the crucial processes like hiring, team formation and workplace interactions in Malaysian ICT

*Corresponding author: Vandana.Saxena@taylors.edu.my 
SMEs, a sector which is believed to employ a diverse workforce drawn from a number of foreign countries. The paper explores the perceptions of the top management vis-a-vis both the 'insider' (the Malaysian employees) the 'outsider' (the foreign employees).

ICT SMEs offer an interesting arena to test the theories of cultural matching. Skilled human capital can be drawn from a vast set of global resources. Hiring foreign workers is a common practice. Subsequent team formations and interactions shape the organizational culture of the said ICT. In Malaysia, Indians and Filipinos form the core ICT workforce. They create a unique work environment where the Malaysian companies and their local employees work alongside the expatriates who are 'experts' in their respective fields of technical knowledge but 'outsiders' to the 'Malaysian' cultural milieu. The dynamics of such multicultural workforce are neither simple nor direct. Several organizational studies have explored the complications that arise from the entry of the cultural outsiders into a relatively homogeneous field $[1,5,12,11]$. This paper adds another dimension to the debate by analyzing the role of culture in processes by which an outsider gains entry and becomes a part of an organization.

The organizations under consideration for this study are service oriented ICT SMEs that have been in business in Malaysia for almost 20 years. They deal with diverse software technologies like Systems, Applications and Products in Data Processing (SAP) and OpenSource Solutions. Providing the case study of the ICT firms, we explore the influence of cultural factors like tastes, language, and geography and so on, on important decisions like hiring, team formations and interactions in order to: -

- determine the extent to which cultural matching influences the entry of a newcomer into the organization,

- understand its influence on the interactions between the team members and the resultant shaping of the work environment.

- to investigate into the way in which the top management's perceptions of cultural diversity influence demographics of the given ICT enterprises.

The study builds on the theories of organizational culture including cultural sociology and social categorization. After a discussion of these theories, the paper highlights the methodology by which the two case studies were chosen, the tools of data collection and the research questions central to this study. A close consideration of the nature of SMEs in Malaysia and the features of the two case studies leads to the final discussion of hiring practices, team formations and group dynamics where culture has a major impact.

\section{Literature Review}

Apart from professional expertise and skills, several other factors influence the newcomers in an organization, right from their entry to their everyday workplace interactions. [13] contends that after taking into account the skill sorting, human capital and social capital during hiring, there is still a great degree of unexplained variance in the process. This, she contends, is because most studies on hiring concentrate on quantitative data available from employers and organizations. For a greater understanding one needs to delve into the process itself, into the perceptions and thought processes that affect the evaluation, comparison and selection of candidates. Impressions conveyed before and during the job interview influence the decision making; 'subjective impressions of candidates that employers develop through interviews are strong drivers of hiring decisions, often carrying more weight than candidate's résumé qualifications' [13]. During the length of the interview, the cultural similarities are subjectively assessed and they become a major factor in the selection of a candidate. Through these observations, Riviera concludes that hiring is 'fundamentally an interpersonal process.' Cultural similarities serve as emotional 
glue generating a feeling of trust and comfort $[4,8,14,16]$, they also become basis to evaluate merit [9]. [7] coined the term 'cultural matchmaking' to highlight the role of culture in the hiring practices. Cultural matching to builds on the theories of social categorization and social identity [17] and the similarity attraction paradigm [3] adding on the dimension of culture and its impact.

While most of these studies talk about cultural aspects of hiring, that is, the process of entry into an organization, this study goes beyond hiring to explore the way culture plays a role in shaping the work environment, the intercultural dynamics and the organizational structure in Malaysia ICT SMEs.

\section{Methodology}

Our data collection was carried out in two ICT SMEs located in the financial hub of Klang Valley in Malaysia. The very nature of the research problem necessitated the use of an inductive qualitative approach. Culture in general is a challenging concept to discuss in a multicultural and fast globalizing context that is Malaysia. [6] have highlighted the importance of using the twin methods of observation and in-depth interviews in the course of researching culture. As culture is often perceived as being a deeply personal feeling, besides being a multi-layered and complex concept to express and understand, we believed that a series of in-depth interviews with the respondents- mostly on an individual basiswould be the best method to unpeel its many layers and interpretations. Following [15], we also placed a great deal of importance to observation as our second technique of data collection. Additionally, we carried out a detailed analysis of the data available on the websites of the SMEs under study.

While both firms operated in similar fields, the workforce of one consisted largely of Malaysian employees, while that of second company consisted largely of foreigners. This differentiation was the critical factor that guided the section of the firms as we were keen to understand the reasons for such divergent workforce demography.

The participants selected for the study were the owners (3), managers (2) and senior employees (5-10) of both firms. At the beginning of fieldwork, the owners of both SMEs were interviewed several times to understand the history of the respective firms. We then selected two team leaders- both of whom were hiring managers- from each SME in order to gather qualitative data that provided us with clues to cultural meanings and interpretations, and a deeper understanding of the background of the respondents themselves.

A small group of employees i.e. IT developers and delivery teams from both SMEs were also interviewed for feedback from 'within' the teams. Observation techniques were extensively used to gather additional and corroborative qualitative insights.

We collected the data over a period of three months during which time we went back to the SMEs several times. The data were analyzed by content analysis from the multimethods used in the qualitative approach.

\section{Key Features and Profile of ICT SME firm}

According to the guidelines issued by the SME Corps, Malaysia in the year 2013, a service sector enterprise can be deemed as an SME if its sales turnover does not exceed RM20 million or the full-time employees are not more than 75. A detailed account of the organizational features of Malaysian ICT SMEs based on the websites of both SMEs and interviews are as follow: 
- They follow an integrated set of human resource policies and practices which work in tandem with the policies of the government. Especially relevant are the policies regarding the hiring of foreign professionals and retaining their services.

- Extreme work pressures and great number of projects require a workforce that is focused on task at hand. For the management as well as the professionals, timely completion of the task is crucial.

- Since the ICT sector in Malaysia is in the growth phase and on the list of Government's high priority sector, the firms need workforce that is creative as well as innovative. Facing the lack of skilled local workforce within Malaysia, ICT firms shop for professionals from countries like India which are a pool of IT resources. In many firms, foreign professionals far outnumber the locals.

- Most of the expatriate population in the ICT sector is transient. Tight financial and budget constraints of an SME affect hiring, contracts, wages and so on. An oft-cited complaint against expatriate ICT professionals in Malaysia is that they see Malaysia as a stepping stone to greener pastures like Singapore. On the other side, the expatriate professionals argue that other places offer them pay commensurate with their expertise. This is an important factor which as we shall see, underpins the attitudes of the local workforce towards the foreigners and also of the foreign professionals towards work, organization and the cultural environment.

\section{Themes}

Despite falling in the broad category of ICT SMEs there are some key differences between two companies chosen for this study. OpenSource solution provider is a medium sized enterprise that caters to a niche market. It boasts of a flexible hierarchy with open channels of communication between different levels of staff. This enables the managers and technical personnel such as developers/consultants to provide comprehensive solutions to the customer's needs.

Started by a local entrepreneur, the company hires through references and the socioprofessional networks of its employees within Malaysia. Majority of the employees are ethnic Malays. Though they move from one team to the other, the employees stay with the company for a long time. Foreign professionals in the company are rare and when hired, they work under Malay team leaders and managers. The company seems satisfied with the local staff but also showed an awareness of future growth trend whereby it would have to open its doors for the foreign professionals soon.

The second organization deals with Systems Applications and Products in Data Processing or SAP solutions, a fiercely competitive segment of ICT industry. Like the earlier company, it tailors its services to the needs and budgets of the clients and provides appropriate expertise to diverse organizations including mid-market companies to larger multinational companies (MNC) and government-linked companies (GLC). The focus is primarily on quality, planning and timely delivery. Most of the staff consists of ICT experts from India. There are also some professionals from Philippines and Malaysia.

Started by a Malaysian entrepreneur of Southern Indian origin, the company hires experts mostly from the south of India, a region which has emerged as a global ICT hub. The practice reflects the wide perception of Indians being the experts in IT industry. During interviews, a Malaysian ICT developer shared that 'Indians as young as 12 or 13 years old were becoming expert developers' whereas in Malaysia 'even ICT graduates possessed limited skills'. He related this to the serious lack of role-models and outstanding leaders in the Malaysian ICT sector. Another source of comparative advantage the Indians possess is the availability of virtual "networks of experts" that they can rely on for troubleshooting technical and computer matters on a daily basis. Hence despite the extra cost and effort 
involved in the hiring of expatriates, Indian IT professionals brought in the advantages that are not available to the local workforce.

However several factors beyond skill set and expertise become operational right from the moment of hiring. The managerial staff and team leaders showed preference for team members who came from the same socio-cultural background hence perpetuating homogeneity. The senior management too seemed aware of these interactional dynamics and the ensuing conflicts arising out of the dominance of one socio-cultural group.

Thus demographic constitution of the two companies offers an interesting case of contrasts and similarities. Though the staff of the two companies differ in their nationalities, both have essentially homogenous teams which are a product of the hiring process and also of the in-group and out-group dynamics which ensures who was hired, retained, and who stayed with the organization for a long term. Selection of 'fit' candidates operated in both the companies, at a conscious and an unconscious level.

The discourse of cultural similarity was found to be structured in the formal and the informal interactions among the employees. It manifested in a variety of interpersonal relationships like friendships, mentoring and techno-social networks. These overlapping themes were expressed largely within the discourse of a family.

\section{Findings: Family, Techno-social Networks and Fitting into the organizational culture}

The discourse of family and familial relationships surfaced repeatedly in the interactions between the employees in the two companies, albeit in different disguises. The seniors in both the organizations assumed the role of the company elders, familiarizing the new employees with the projects, organizational structure and generally helping them find their feet in the new work environment. This interpersonal relationship worked at professional and personal level. The seniors 'looked after' the newcomers not only during the working hours but also during the leisure time and after work hours. Eating together, meeting over the weekends, co-planning leisure activities - it seemed as crucial to initiate the newcomers in these in-group activities as it was to introduce them to the project.

In the company with the predominance of Malaysian employees, the perception of organization as a family existed alongside the perception of the foreigner as almost an intruder. It came across in the main complaint against the foreign employees. One of the senior managers told us that 'they (generally) don't have a strong sense of belonging.' 'It is because they don't socialize much (with locals),' a young Malay team leader added. 'They tend to work alone. It sometimes creates problems.'

At the professional level, the complaint was concerned with the noncompliance to the standard methods and ways of handling the projects, writing the programs and so on. 'This creates problems in the later audit and maintenance stage,' the team leader confided. 'We don't know how to fix a program because they haven't done it the way we do... wastes a lot of time.'

The tendency to 'work alone' trickled from the official to non-official interactions. While foreign professionals tend to focus on completing the projects, the local employees looked forward to social and personal interactions, eating together during lunch times and other such common activities. Religious and food taboos also emerged as points of contention. Foreign professionals and the local employees often ate separately, a tendency viewed with annoyance among the local employees. 'We are not hiring robots,' opined one of the local managers.

Beneath the complaint, there were noticeable undercurrents of the dominance of the majority. The onus of 'fitting -in' the organizational 'family' lay with the expatriate employees. They were expected to follow the codes of the majority. For instance, when a 
Chinese employee brought pork for lunch, the manager had to tell him that he could eat pork but not mention it or eat with others.

Another issue of contention was the lack of cultural awareness among the newcomers. It was cited as a major problem of the expatriate professionals coming to Malaysia. 'A little example,' the team leader told the researchers, 'the foreigners are not aware that government clients cannot be called during the time of Maghreb or the evening prayer. A local employee knows these things automatically.'

Thus foreign professionals are seen as intruders in the "warm" "family-like" environment, and often stereotyped as being culturally insensitive or 'awkward'. The case of the sole woman employee in the staff offered an interesting insight. She is a fresher and a foreigner and she has been living in Malaysia for nearly twenty years. With her knowledge of the local language and customs, she 'fitted- in' the organization. She undertook the job of taking care of the visitors, the refreshments and other duties of hospitality. The senior manager advised her to marry a Malaysian. 'This,' she laughed 'was an everyday talk. I have a father here."

Similar family discourse was evident in the second company which consisted primarily Indian professionals (and a small group from the Philippines). Working away from home, the expatriate managers and professionals tended to create a home-like atmosphere by finding people of their own kind and sticking with them.

The company was started by a Malaysian entrepreneur of South Indian (Kerala) origin in the late 1990s, approximately at the same time when unprecedented upsurge in the field of Information Technology began in India. Apart from technical expertise, one of the main criterion of hiring was extended family or close friends 'back home ' ('from my village in India") or people that he could personally vouch for or trust. Over the years, this expanded to include those similar in the regional, linguistic and cultural background.

The trend continues to dominate. As the organization has grown, the power of decision making has trickled down from the senior management to the hiring managers and project leaders. Yet the project managers prefer to work with team members who come from same region and culture. The young professionals hired from India also gravitate towards the seniors who hail from similar cultural background.

Like the earlier case study, the set-up echoed the structure of a close-knit family with the hiring managers and project leaders assuming a paternal role, expecting obedience and gratitude from their protégés and at the same time, 'looking after them' in the foreign land. Thus the mentoring extended beyond the professional sphere into the personal arena. Food, housing (most prefer to live in close proximity to each other) and leisure glued the team together.

The expatriate hiring managers revealed their positive perceptions of the new hires from their own ethnic groups. The Indian hiring managers and project managers found it easier to communicate effectively and easily with the employees of similar social, cultural and regional background. Their higher degree of technical expertise, similarities in working patterns, effective delivery -were cited as major advantages to the team. The individual work teams communicated in their own mother-tongue within and across teams, for example in Telugu or Malayalam, with scant regard for minority team members who belonged to other ethnic groups even among the Indians themselves. Such linguistic collusion was a common mode of creating in-groups and out-groups.

Though the teams worked in harmony, the dominance of one ethnic group sometimes created friction or competition within the organization. One of the employees from another nationality shared that the 'Indians wanted to form their own groups, and stick to it. They did not want to merge with the local population.' Other commonly held perceptions about Indians were that their sense of timing was different from Malaysians that they promised much more than they could actually deliver, that many of them spoke English with thick 
local accents which were often difficult for Malaysians to understand. According to the senior management, this friction among the staff members was a major complication since the company employees are foreign as well as local, based on market expertise and latest demands of the ICT industry.

Thus the companies face a new dilemma today. Whereas the senior level Malaysian staff has reservations about hiring expatriates from the same region, the expatriate hiring managers look deep into their own socio-ethnic network for a 'good fit' in the existing teams. Even when the management hired professionals from other nationalities and cultures, these new professionals found themselves excluded from the teams and its ingroup networks, leading to problems like communication gap and employee dissatisfaction. Eventually, the employees who did not 'fit,' left.. One outgoing Malaysian professional (a minority in this SME) complained that his boss treated the Indians and non-Indians differently. He cited this as one of the major reasons for quitting the organization.

\section{Implications: Similarities and distinctive characteristics}

Despite the difference in the composition of the workforce, the two SMEs showed a remarkable degree of similarity in their day to day functions, employee perceptions as well as the problems they encounter in face of growing diversity in the ICT sector. Competing with the multinationals in the ICT field, the thrust was on the qualities of loyalty and sense of belonging. The right 'fit' into the work culture is as important as the professional expertise. Furthermore, hiring through their 'techno-social networks' with references from friends, family and hometown created value additional to the merit of the candidate [6]. Thus social and cultural similarities served as 'powerful emotional glue that facilitates trust and comfort, generates feelings of excitement and bonds individuals together' [13].

The model of a family emerged time and again, in overt discussions and also as underlying subtext in other situations and utterances. Instead of a clearly defined professional role, the employees played the part of family members. The older members and mentors undertook the role of family elders, helping, guiding and at times chastising the new employees. The new employees, in turn, fitted in the with the older member's perception by being loyal to their senior managers.

The notion of fitting together worked at organizational as well as the emotional level extending the sense of security to the employees but at the same time perpetuating homogeneity. Culturally similar employees were seen to strengthen the harmony in the organization and enhance team productivity by minimizing conflict of the team. On the individual level, the team members seemed secure, confident and at ease with each other. Cultural outsiders were perceived as intruders in the warm atmosphere of the company.

Apart from these similarities, the two SMEs showed some distinctive features due to the nature of the hiring process. While the company with predominantly local population hired long term employees and look forward to long lasting associations, the expatriates in the other company were hired on short term contracts. Most of them created short term relationships with their own kind, concentrating on the work and being more concerned about the project and money rather than fitting and adjusting to the new cultural environment. Loyalty when it surfaced was directed towards the project managers who belonged to same socio-cultural background instead of the company at large.

\section{Conclusion}

Two SMEs under consideration for this study stand at similar crossroads that the Malaysian ICT sector faces on a larger level. They are poised at the level of enterprise 
growth where looking beyond the network of family and friends for hiring is crucial to expand and compete within the market driven ICT sector. Despite its wariness, the company dominated by Malaysian employees is planning to expand and hire foreign employees. 'It is inevitable,' said one of managers recognizing the need of the hour. The other SME has already taken the plunge. Moving beyond Malaysia to enlarge its talent pool, it now faces issues that expatriate employment brings. At the moment it is dealing with the power struggles that diversity brings.

The cultural interactions within these SMEs provided an interesting study to test the theory of cultural matching. According to Rivera, cultural similarities affect the organizational processes, the cognitive processes, and the affective processes during the process of hiring. Considering the organizational processes in the Malay dominated SME, the thesis was found to be largely true since the organizational set up is small. The thrust is on finding the candidate who 'fits' into the organizational 'family.' In case of the second SME, the study revealed that as the organization grows beyond the local confines, skill set becomes as important as cultural matching. The regional dominance of Indian professionals is a result of their skills and expertise as much as their cultural background.

The study also revealed that the process of cultural matching is active before the process of hiring and remain so long after it. Experiences in the past, observations of the environment around, open and covert conflicts - all these create the perceptions through which the candidates are evaluated. These perceptions shape the idea of the right 'fit' even before the candidate or the vacancy materializes. These social and cultural factors also played a major role in creating a conducive work environment for some employees while excluding the others. Hence cultural matching had a determining influence in the power struggles within an organization and shaped its ethnic demographics.

\section{Acknowledgements}

This study was supported by a Fundamental Research Grant (FRGS/2/2013/SSI08/TAYLOR/02/1) of the Ministry of Higher Education, Malaysia.

\section{References}

1. L. Argote, D. H. Gruenfeld, C. Naquin. 'Group learning in organizations.' In M. Turner (Ed.), Groups at work: Theory and Research (369-411). Mahwah, NJ (2001).

2. Blau, Peter, Duncan, Otis. The American Occupational Structure. Free Press (1967)

3. D.Byrne. The Attraction Paradigm. Academic Press (1971).

4. R. Collins. Interaction Ritual Chains. Princeton University Press (2004)

5. T. H. Cox, S. A. Lobe, P, L McLeod. 'Effects of Ethnic Group Cultural Differences on Cooperative and Competitive Behavior on a Group Task'. AMJ, 34, 4 827-847 (1991)

6. S. Selvadurai, A. Dasgupta. Culturally Diverse Teams and Social Interaction Influence on Team Effectiveness in Small and Medium Enterprises in the ICT Sector in Malaysia, Millennial Asia April 2016 7: 42-62, Sage Publications ( 2016)

7. P. DiMaggio. "Nadel's Paradox Revisited: Relational and Cultural Aspects of Social Structure." In Nohria and Eccles (Ed.) Networks and Organizations: Structure, Form and Action. 118-42 HBS Press. (1992)

8. B. Erickson. "Culture, Class, and Connections." AJS 102, 217-51 (1996).

9. M. Lamont, M. Vira. "The Study of Boundaries in the Social Sciences." ARS 28,16795 (2002) 
10. A. Lareau, W. Elliot. "Cultural Capital in Educational Research: A Critical Assessment." Theory and Society 32,567-606 (2003).

11. F. Milliken, L. Martins. 'Searching for common threads: understanding the multiple effects of diversity in organizational groups.' AMR 21, 402-433 (1996).

12. K. W. Phillips, A. L. Katie, A. N. Margaret. 'Is the Pain Worth the Gain? The Advantages and Liabilities of Agreeing with Socially Distinct Newcomers. Personality and Social Psychology Bulletin. 35, 336-350 (2009)

13. L. A. Rivera. 'Hiring as Cultural Matching: The Case of Elite Professional Service Firms.' ASR 77, 999-1022 (2012)

14. V. Roscigno. The Face of Discrimination: How Race and Gender Impact Work and Home Lives. Rowman (2007).

15. S. Selvadurai, D. Anindita 2016. "Culturally Diverse Teams and Social Interaction Influence on Team Effectiveness in Small and Medium Enterprises in the ICT Sector in Malaysia." Millenial Asia 7(1), 1-12 (2016)

16. K. Stainback, T. D. Donald, S. Sheryl "Organizational Approaches to Inequality: Inertia, Relative Power, and Environments.” ARS 36, 225-47 (2010).

17. H. Tajfel, T. John. "The Social Identity Theory of Intergroup Behavior." In Worsheland and Austin (Ed.) Psychology of Intergroup Relations. Nelson-Hall,7-24 (1986)

18. C. Tilly, C. Tilly. Work under Capitalism. Westview Press (1998). 